\title{
Experimental studies on a vapour compression system using nanorefrigerants
}

\author{
N. Subramani ${ }^{1}$, M. J. Prakash ${ }^{2 *}$ \\ Department of Mechanical Engineering, TKM College of Engineering, Kollam - 691 005, Kerala, INDIA \\ *Corresponding author e-mail: jpmmech@yahoo.co.in, Tel +91-9447450632, Fax. +91-474-2712023
}

\begin{abstract}
Convective heat transfer is very important in the HVAC, refrigeration and microelectronics cooling applications. R134a is most widely adopted alternate refrigerant in refrigeration equipment, such s domestic refrigerators and air conditioners. Though the global warming up potential of R134a is relatively high, it is affirmed that it is a long term alternate refrigerants in lots of countries. The addition of nanoparticles to the refrigerant results in improvements in the thermophysical properties and heat transfer characteristics of the refrigerant, there by improving the performance of the refrigeration system. Stable nanolubricant has been prepared for the study. The experimental studies indicate that the refrigeration system with nanorefrigerant works normally. It is found that the freezing capacity is higher and the power consumption reduces by $25 \%$ when POE oil is replaced by a mixture of mineral oil and alumina nanoparticles. Calculations show that the enhancement factor in the evaporator is 1.53 when nanorefrigerants are used instead of pure refrigerant.
\end{abstract}

Keywords: Nanofluids, thermal conductivity, heat transfer coefficient, freezing capacity, COP.

DOI: http://dx.doi.org/10.4314/ijest.v3i9.8

\section{Introduction}

It is true that rapid industrialization has led to unprecedented growth, development and technological advancement across the globe. It has also given rise to several new concerns. Today global warming and ozone layer depletion on the one hand and spiraling oil prices on the other hand have become main challenges. Excessive use of fossil fuels is leading to their sharp diminution and nuclear energy is not out of harm's way. In the face of imminent energy resource crunch there is need for developing thermal systems which are energy efficient. Thermal systems like refrigerators and air conditioners consume large amount of electric power. So avenues of developing energy efficient refrigeration and air conditioning systems with nature friendly refrigerants need to be explored

The rapid advances in nanotechnology have lead to emerging of new generation heat transfer fluids called nanofluids. Nanofluids are prepared by suspending nano sized particles $(1-100 \mathrm{~nm})$ in conventional fluids and have higher thermal conductivity than the base fluids. Nanofluids have the following characteristics compared to the normal solid liquid suspensions. i) higher heat transfer between the particles and fluids due to the high surface area of the particles ii) better dispersion stability with predominant Brownian motion iii)reduces particle clogging iv) reduced pumping power as compared to base fluid to obtain equivalent heat transfer. Based on the applications, nanoparticles are currently made out of a very wide variety of materials, the most common of the new generation of nanoparticles being ceramics, which are best split into metal oxide ceramics, such as titanium, zinc, aluminium and iron oxides, to name a prominent few and silicate nanoparticles, generally in the form of nanoscale flakes of clay. Addition of nanoparticles changes the boiling characteristics of the base fluids. Nanoparticles can be used in refrigeration systems because of its remarkable improvement in thermophysical and heat transfer capabilities to enhance the performance of refrigeration systems. In a vapour compression refrigeration system the nanoparticles can be added to the lubricant (compressor 
oil). When the refrigerant is circulated through the compressor it carries traces of lubricant + nanoparticles mixture (nanolubricants) so that the other parts of the system will have nanolubricant -refrigerant mixture.

Recently, some investigators have conducted studies on vapour compression refrigeration systems, to study the effect of nanoparticle in the refrigerant/lubricant on its performance. Pawel et al. (2005) conducted studies on nanofluids and found that there is the significant increase in the thermal conductivity of nanofluid compared to the base fluid. They also found that addition of nanoparticles results in significant increase in the critical heat flux. Bi et al. (2007) conducted studies on a domestic refrigerator using nanorefrigerants. In their studies $\mathrm{R} 134 \mathrm{a}$ was used the refrigerant, and a mixture of mineral oil $\mathrm{TiO}_{2}$ was used as the lubricant. They found that the refrigeration system with the nanorefrigerant worked normally and efficiently and the energy consumption reduces by $21.2 \%$. When compared with $\mathrm{R} 134 \mathrm{a} / \mathrm{POE}$ oil system. Later, Bi et al. (2008) found that there is remarkable reduction in the power consumption and significant improvement in freezing capacity. They pointed out the improvement in the system performance is due to better thermo physical properties of mineral oil and the presence of nanoparticles in the refrigerant.

Jwo et al. (2009) conducted studies on a refrigeration system replacing R-134a refrigerant and polyester lubricant with a hydrocarbon refrigerant and mineral lubricant. The mineral lubricant included added $\mathrm{Al}_{2} \mathrm{O}_{3}$ nanoparticles to improve the lubrication and heat-transfer performance. Their studies show that the $60 \% \mathrm{R}-134 \mathrm{a}$ and $0.1 \mathrm{wt} \% \mathrm{Al}_{2} \mathrm{O}_{3}$ nanoparticles were optimal. Under these conditions, the power consumption was reduced by about $2.4 \%$, and the coefficient of performance was increased by $4.4 \%$. Peng et al. (2010) conducted experimental on the nucleate pool boiling heat transfer characteristics of refrigerant/oil mixture with diamond nano particles. The refrigerant used was R113 and the oil was VG68. They found out that the nucleate pool boiling heat transfer coefficient of R113/oil mixture with diamond nanoparticles is larger than the R113/oil mixture. They also proposed a general correlation for predicting the nucleate pool boiling heat transfer coefficient of refrigerant/oil mixture with nanoparticles, which well satisfies their experimental results.

Henderson et al. (2010) conducted an experimental analysis on the flow boiling heat transfer of R134a based nanofluids in a horizontal tube. They found excellent dispersion of $\mathrm{CuO}$ nanoparticle with $\mathrm{R} 134 \mathrm{a}$ and POE oil and the heat transfer coefficient increases more than $100 \%$ over baseline R134a/POE oil results. Bobbo et al. (2010) conducted a study on the influence of dispersion of single wall carbon nanohorns $(\mathrm{SWCNH})$ and $\mathrm{TiO} 2$ on the tribological properties of POE oil together with the effects on the solubility of R134a at different temperatures. They showed that the tribological behaviour of the base lubricant can be either improved or worsen by adding nanoparticles. On the other hand the nanoparticle dispersion did not affect significantly the solubility. Bi et al. (2011) conducted an experimental study on the performance of a domestic refrigerator using TiO2-R600a nanorefrigerant as working fluid. They showed that the TiO2-R600a system worked normally and efficiently in the refrigerator and an energy saving of $9.6 \%$. They too cited that the freezing velocity of nano refrigerating system was more than that with pure R600a system. The purpose of this article is to report the results obtained from the experimental studies on a vapour compression system. In the present study the refrigerant selected is R134a and the nanoparticle is alumina.

\section{Experimental setup}

For the studies a refrigeration test rig was designed and fabricated. The test rig consists of a compressor, air-cooled condenser, thermostatic expansion valve and an evaporator. The compressor used is a hermetically sealed reciprocating compressor. The evaporator is in the form of a cylindrical spiral coil and is completely immersed in water (cooling load) and it is made of copper. A serpentine coil finned tube heat exchanger is used as the condenser and it is also made of copper. The condenser is cooled using a fan.

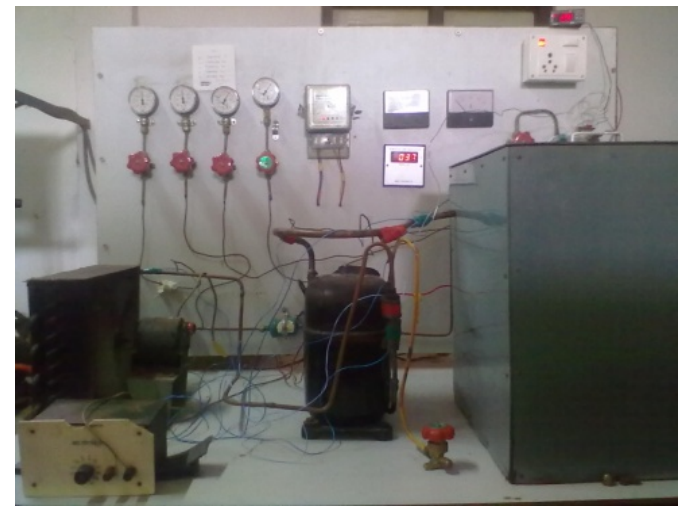

Figure 1. Photograph of the experimental set up 
The Bourden tube pressure gauges are used to measure the pressures at the salient points of the refrigeration system, one each at the outlets of compressor, condenser, expansion device and evaporator. T- type thermocouples (36 SWG) were used to measure the temperature at the various locations. Prior to experimental measurements the thermocouples were calibrated using a constant temperature bath (JulaboF25). The temperature data was acquired using a temperature scanner. The power consumption of the compressor is measured using a digital energy meter. The experimental setup used for the present study is shown in Figure 1 Before charging the test rig with the refrigerant, the system was checked thoroughly for leaks. Leak testing was carried out by charging the system with nitrogen at a pressure of 200 Psi. After the leak test the system was properly evacuated using a vacuum pump. The compressor was filled with nanolubricant and the system was charged with the refrigerant, in this case R134a

\section{Preparation of nanoparticles compressor oil mixture (nanolubricant)}

Preparation of nanolubricants is the first step in the experimental studies on nanorefrigerants. Nanofluids are not simply liquidsolid mixtures. Special requirements are even, stable and durable suspension, negligible agglomeration of particles, and no chemical change of the fluid. Nanofluids can be prepared using single step or two step methods. In the present study two step procedure is used. Commercially available nanoparticles of aluminium oxide (manufactured by Sigma Aldrich) with average size $<50 \mathrm{~nm}$ and having density $0.26 \mathrm{~g} / \mathrm{cc}$ were used for the preparation of nanolubricant. Mass fraction of nanoparticles in the nanoparticle-lubricant mixtures is $0.06 \%$. An ultrasonic vibrator (Micro clean 102, Oscar Ultrasonics) was used for the uniform dispersion of the nanoparticles and it took about 24 hours of agitation to achieve the same. Experimental observation shows that the stable dispersion of alumina nanoparticles can be kept for more than 3 days without coagulation or deposition.

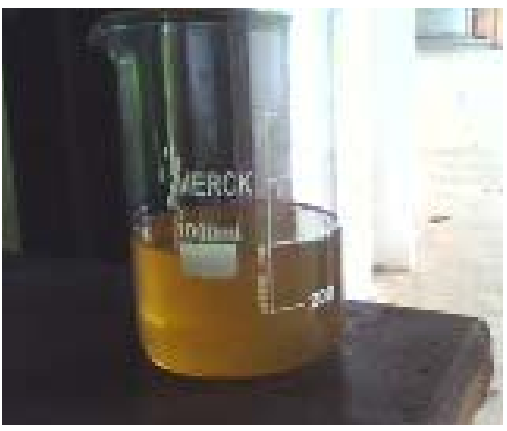

(a)

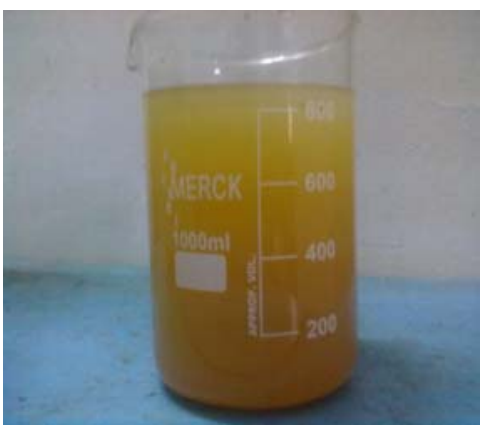

(b)

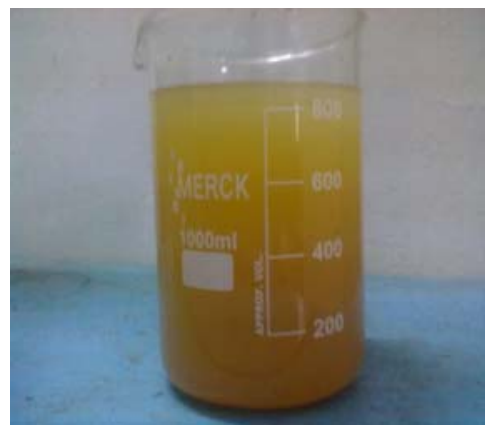

(c)

Figure 2. Photographs of nanolubricant (a) pure lubricant (b) after 24 hours of ultrasonic agitation (c) 3 days after ultrasonic agitation

\section{Theoretical Analysis}

In order to estimate the heat transfer coefficient in the refrigerant side of the evaporator the thermophysical properties of the nanorefrigerant have to be calculated. The thermophysical properties of the nanorefrigerant are calculated in two steps. Firstly thermophysical properties of the nanoparticles oil mixture is calculated and this data is used to calculate the properties of nanorefrigerant.

\subsection{Calculation of thermophysical properties of nanolubricant}

The following correlations are used to calculate the thermophysical properties of nanolubricant

Specific heat of nanolubricant $C p_{n, 0}=\left(1-\psi_{n}\right) C p_{o}+\psi_{n} C p_{n}$ (Pak and Cho, 1998)

Thermal conductivity nanolubricanr, $\mathrm{K}_{\mathrm{n}, \mathrm{o}}=\mathrm{K}_{\mathrm{o}}\left[\left(\mathrm{K}_{\mathrm{n}}+2 \mathrm{~K}_{\mathrm{o}}-2 \psi_{\mathrm{n}}\left(\mathrm{K}_{\mathrm{o}}-\mathrm{K}_{\mathrm{n}}\right)\right) /\left(\mathrm{K}_{\mathrm{n}}+2 \mathrm{~K}_{\mathrm{o}}+\psi_{\mathrm{n}}\left(\mathrm{K}_{\mathrm{o}}-\mathrm{K}_{\mathrm{n}}\right)\right)\right]$ (Hamilton and Crosser, 1962)(2)

Viscosity of nanolubricant, $\mu_{\mathrm{n}, \mathrm{o}}=\mu_{\mathrm{o}}\left[1 /\left(1-\psi_{\mathrm{n}}\right)^{2.5}\right]$ (Brinkman, 1952)

Density of nanolubricant, $\rho_{\mathrm{n}, \mathrm{o}}=\left(1-\psi_{\mathrm{n}}\right) \rho_{\mathrm{o}}+\psi_{\mathrm{n}} \rho_{\mathrm{n}}$,

Volume fraction of nanoparticle in the nanoparticle-oil suspension,

$$
\psi_{\mathrm{n}}=\omega_{\mathrm{n}} \rho_{\mathrm{o}} /\left[\omega_{\mathrm{n}} \rho_{\mathrm{o}}+\left(1-\omega_{\mathrm{n}}\right) \rho_{\mathrm{n}}\right]
$$

Mass fraction in the nanoparticle oil suspension,

$$
\omega_{\mathrm{n}}=\mathrm{m}_{\mathrm{n}} /\left(\mathrm{m}_{\mathrm{n}}+\mathrm{m}_{\mathrm{o}}\right)
$$

4.2.Calculation of thermophysical properties nanorefrigerant

Specific heat of the nanorefrigerants $\mathrm{Cp}_{\mathrm{r}, \mathrm{r}, \mathrm{n}, \mathrm{f}}=\left(1-\mathrm{X}_{\mathrm{n}, \mathrm{o}}\right) \mathrm{Cp}_{\mathrm{r}, \mathrm{f}}+\mathrm{X}_{\mathrm{n}, \mathrm{o}} \mathrm{Cp}_{\mathrm{n}, \mathrm{o}, \mathrm{o}}$, (Jensen and Jackman, 1984)

Viscosity of the nanorefrigerants $\mu_{\mathrm{r}, \mathrm{n}, \mathrm{o}, \mathrm{f}}=\exp \left(\mathrm{X}_{\mathrm{n}, \mathrm{o}} \ln \mu_{\mathrm{n}, \mathrm{o}}+(1-\mathrm{Xn}, \mathrm{o}) \ln \mu_{\mathrm{r}, \mathrm{f}}\right)$, (Kedzierski and Kaul, 1993)

Thermal conductivity of the nanorefrigerants 
$\mathrm{K}_{\mathrm{r}, \mathrm{n}, \mathrm{o}, \mathrm{f}}=\mathrm{K}_{\mathrm{r}, \mathrm{f}}\left(1-\mathrm{X}_{\mathrm{n}, \mathrm{o}}\right)+\left(\mathrm{K}_{\mathrm{n}, \mathrm{o}} \mathrm{X}_{\mathrm{n}, \mathrm{o}}\right)-\left(0.72 \mathrm{X}_{\mathrm{n}, \mathrm{o}}\left(1-\mathrm{X}_{\mathrm{n}, \mathrm{o}}\right)\left(\mathrm{K}_{\mathrm{n}, \mathrm{o}}-\mathrm{K}_{\mathrm{r}, \mathrm{f}}\right)\right)$, (Baustian et. al, 1988)

Density of the nanorefrigerants $\rho_{\mathrm{r}, \mathrm{n}, \mathrm{o}, \mathrm{f}}=\left[\left(\mathrm{X}_{\mathrm{n}, \mathrm{o}} / \rho_{\mathrm{n}, \mathrm{o}}\right)+\left(\left(1-\mathrm{X}_{\mathrm{n}, \mathrm{o}}\right) / \rho_{\mathrm{r}, \mathrm{f}}\right)\right]^{-1}$

Nanoparticle/oil suspension concentration, $\mathrm{X}_{\mathrm{n}, \mathrm{o}}=\mathrm{m}_{\mathrm{n}, \mathrm{o}} /\left(\mathrm{m}_{\mathrm{n}, \mathrm{o}}+\mathrm{m}_{\mathrm{r}}\right)$

4.3 Calculation of heat flux and transfer coefficient in the refrigerant side of the evaporator

The heat flux (q) is calculated from the formula proposed by Peng et al. (2010)

$$
\Delta \mathrm{T}_{\mathrm{b}}=\frac{\mathrm{C}_{\mathrm{sf}} \mathrm{h}_{\mathrm{fg}}}{\mathrm{C}_{\mathrm{p}, \mathrm{r}, \mathrm{n}, \mathrm{o}, \mathrm{f}}}\left[\frac{\mathrm{q}}{\mu_{\mathrm{r}, \mathrm{n}, \mathrm{o}, \mathrm{f}} \mathrm{h}_{\mathrm{fg}}} \sqrt{\frac{\sigma_{\mathrm{r}, \mathrm{n}, \mathrm{o}}}{\mathrm{g}\left(\rho_{\mathrm{r}, \mathrm{n}, \mathrm{o}, \mathrm{f}}-\rho_{\mathrm{r}, \mathrm{g}}\right)}}\right]^{0.33}\left[\frac{\mathrm{C}_{\mathrm{p}, \mathrm{r}, \mathrm{n}, \mathrm{o}, \mathrm{f}} \mu_{\mathrm{r}, \mathrm{n}, \mathrm{o}, \mathrm{f}}}{\mathrm{K}_{\mathrm{r}, \mathrm{n}, \mathrm{o}, \mathrm{f}}}\right]^{\mathrm{n}}
$$

$\Delta \mathrm{T}_{\mathrm{b}}=\mathrm{T}_{\mathrm{w}}-\mathrm{T}_{\mathrm{sat}}$

Surface tension of nanorefrigerants $\sigma_{\mathrm{r}, \mathrm{n}, \mathrm{o}}=\sigma_{\mathrm{r}}+\left(\sigma_{\mathrm{n}, \mathrm{o}}-\sigma_{\mathrm{r}}\right) \mathrm{X}_{\mathrm{n}, \mathrm{o}}{ }^{0.5}$, (Jensen and Jackman, 1984)

$\mathbf{C}_{\text {sf }}=\exp \left(-8.062-1.789 \omega_{\mathrm{n}}+2.786 \mathrm{X}_{\mathrm{n}, \mathrm{o}}\right)$ and $\mathrm{n}=1.085$

The nucleate pool boiling heat transfer coefficient of refrigerant/oil mixture with nano particles,

$\mathrm{h}_{\mathrm{r}, \mathrm{n}, \mathrm{o}}=\mathrm{q} / \Delta \mathrm{T}_{\mathrm{b}}$

The value of heat transfer coefficient without nanoparticles is calculated using the boiling correlations for conventional refrigerants

The energy enhancement factor(E.F) is calculated using the equation $E . F=h_{r, n, o} / h_{r, o}$

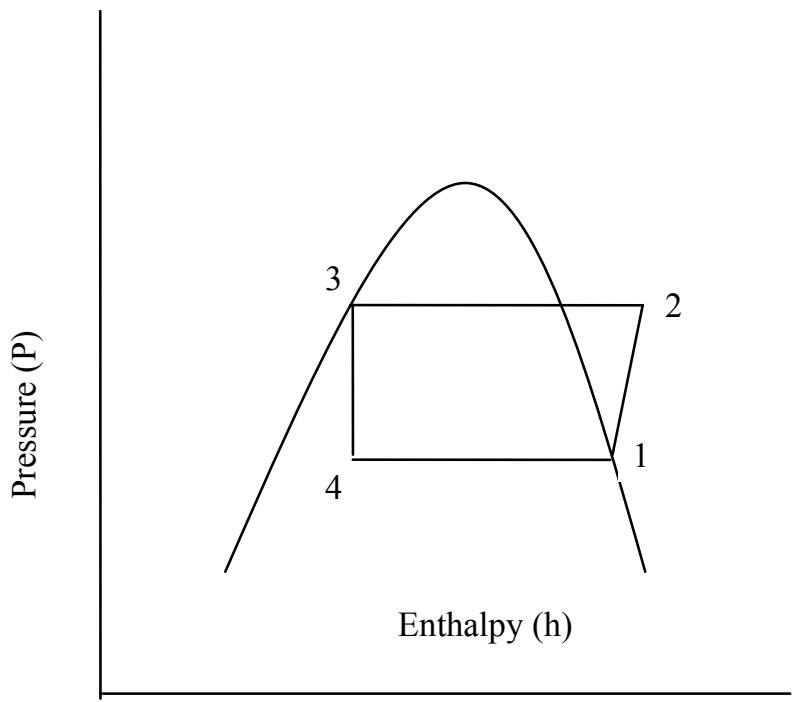

Figure 3. Pressure enthalpy diagram of the vapour compression cycle

Figure 3 shows the pressure enthalpy diagram of an ideal vapour compression refrigeration system. Here process 1-2 is the compression process in the compressor , 2-3 is the condensation process, 3-4 is the expansion process in the expansion device and 4-1 is the evaporation process.

The theoretical C.O.P is calculated using the equation C.O.P $\mathrm{P}_{\mathrm{th}}=\left(\mathrm{h}_{1}-\mathrm{h}_{4}\right) /\left(\mathrm{h}_{2}-\mathrm{h}_{1}\right)$

$\mathrm{h}_{1}$ - enthalpy of refrigerant at the inlet of the compressor

$\mathrm{h}_{2}$ - enthalpy of refrigerant at the outlet of the compressor

$\mathrm{h}_{4}$ - enthalpy of refrigerant at the inlet of the evaporator

the values of the enthalpy are taken from refrigerant tables.

The actual C.O.P is calculated using relation C.O.P ${ }_{\text {act }}=$ cooling load $/$ power input

\section{Results and discussion}

In the present experimental study, three cases have been considered. The hermetic compressor filled with i) pure POE oil ii) SUNISO 3GS oil (mineral oil) and iii) SUNISO 3GS+ alumina nanoparticles as lubricant. The mass fraction of the nanoparticles in the nanolubricant is $0.06 \%$. 


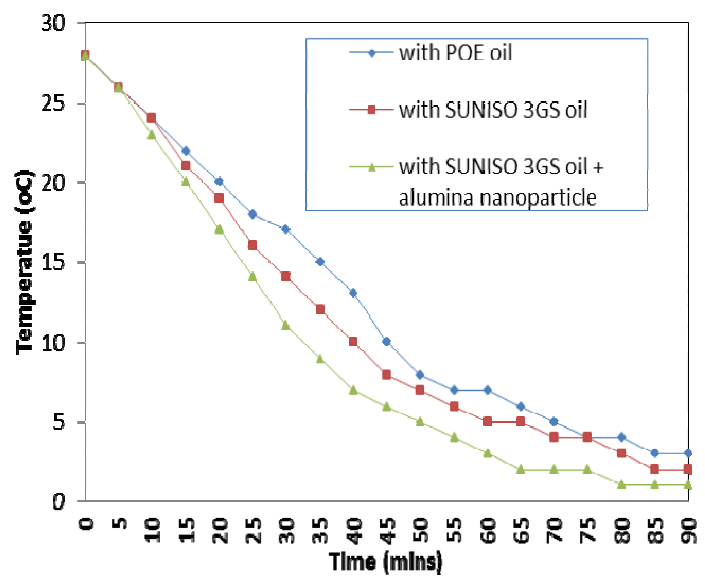

Fig.4:Temperature-Time history

Theoretical analysis shows that the enhancement factor in the evaporator with nanorefrigerant is 1.53 or in other words the heat transfer coefficient increases by 53\% when nanorefrigerant is used instead of R134a. The value of heat transfer coefficient without nanoparticles is calculated using the boiling correlations for conventional refrigerants and its value is found to be 1612 $\mathrm{W} / \mathrm{m}^{2} \mathrm{~K}$. Peng et a. (2009) have reported that the value of energy enhance factor is in the range $1.17-1.63$. The cooling load temperature - time history is shown in figure. 4 and the freezing capacity for the three cases is shown in Figure.5. In all the cases the condenser pressure is $1.2 \mathrm{MPa}(180 \mathrm{Psi})$ and the evaporator pressure is $0.2 \mathrm{MPa}(30 \mathrm{Psi})$. No appreciable pressure drops due to friction were observed in the condenser and evaporator. From the figure it is clear that, the time required for reducing cooling load temperature is less for the SUNISO 3GS oil + alumina nanoparticle mixture. For example, with SUNISO 3GS oil + alumina nanoparticle, the time required to bring the cooling load temperature from $28^{\circ} \mathrm{C}$ to $5^{\circ} \mathrm{C}$ is 50 minutes where as that with SUNISO $3 \mathrm{GS}$ and POE oil is 60 and 70 minutes respectively.

It is clear that, the freezing capacity of the SUNISO 3GS + Alumina nanoparticle mixture is higher when compared with the other two cases The time taken to reduce the temperature of the cooling load from $28{ }^{\circ} \mathrm{C}$ to $1{ }^{\circ} \mathrm{C}$ with POE oil is 110 minutes and it reduces by $27 \%$ if SUNINSO 3 GS oil + alumina nanoparticle is used. This is due to the fact the nanoparticles present in the refrigerant enhances the heat transfer rate in the refrigerant side of the evaporator

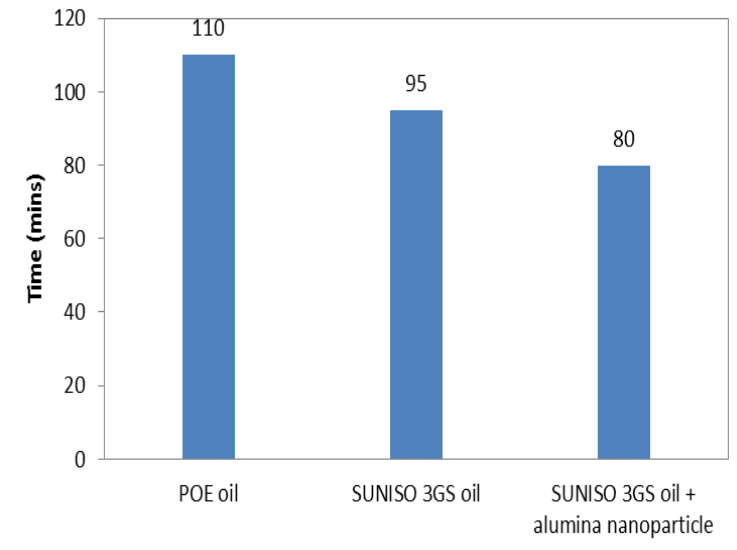

Fig.5 Effect of nanoparticle on the freezing Capacity

Figure 6 shows drop in the refrigerant temperature in the condenser of the refrigeration system. Temperature drop of the refrigerant is high with nanorefrigerant when compared with the other cases The temperature of the refrigerant at the inlet of the condenser is in the range $85-80^{\circ} \mathrm{C}$. The saturation temperature of $\mathrm{R} 134 \mathrm{~A}$ corresponding to the condenser pressure of $1.2 \mathrm{MPa}$ is $46.3^{\circ} \mathrm{C}$. In the case of SUNISO 3GS nanoparticle mixture the temperature at the exit of the condenser is $38{ }^{\circ} \mathrm{C}$ and the subcooling obtained is $8.3^{\circ} \mathrm{C}$. In fact there is no subcooling when POE oil is used as the lubricant. The enhanced heat transfer rate in the condenser is due to the presence of nanoparticles in the refrigerant. 


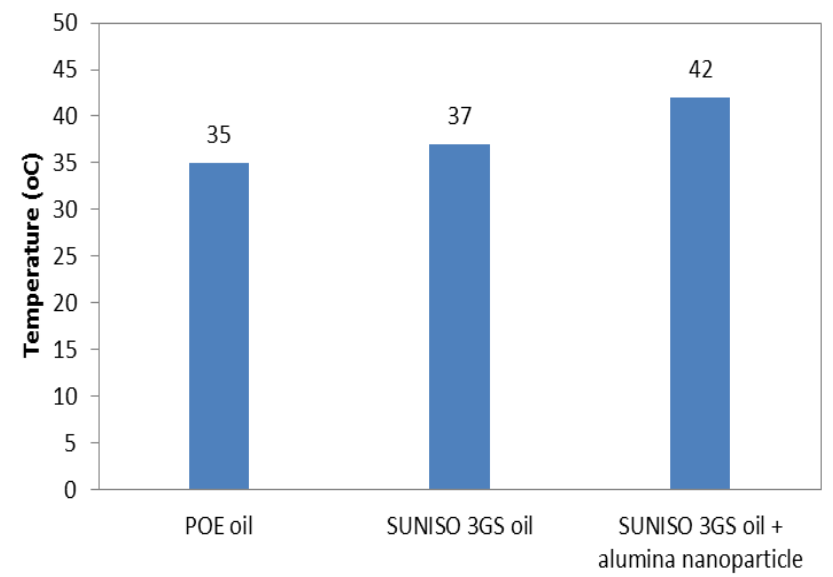

Figure 6. Reduction in refrigerant temperature while passing through condenser

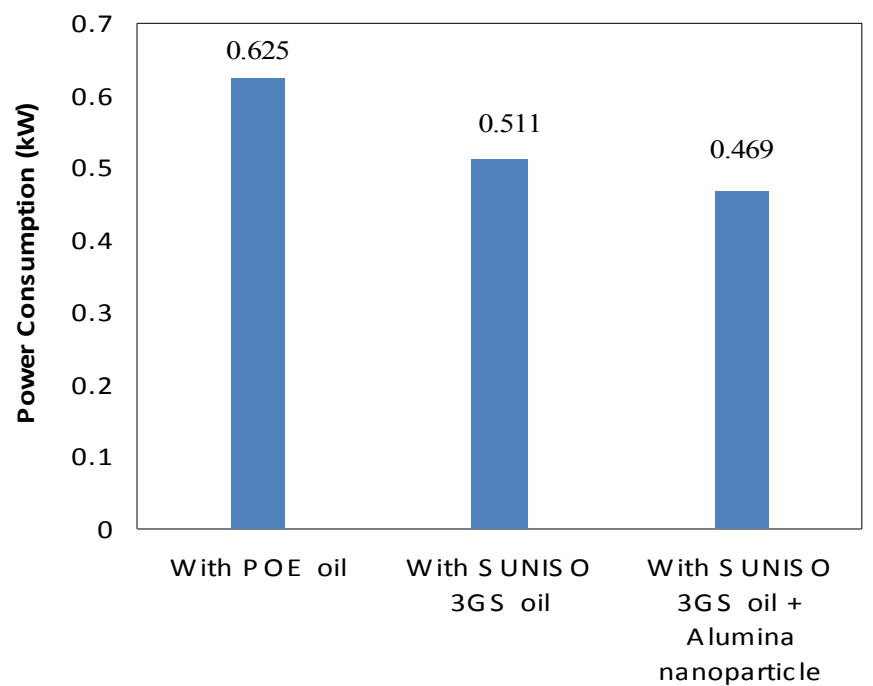

Figure 7. Comparison of power consumption

Figure 7 shows the comparison of power consumption of the compressor . The reduction in power consumption is $18 \%$ if the SUSISO $3 \mathrm{GS}$ is used instead of POE Oil and a reduction of 25\% is observed when SUNISO 3GS is mixed nanoparticles. Bi et al. (2007) reported that for a refrigeration system using R134a as refrigerant the power consumption can be reduced by $26.1 \%$ if mineral oil with $\mathrm{TiO}_{2}$ nanoparticle is used instead of POE oil. Figure 8 shows the coefficient of performance (COP) calculated using the experimental data. The actual COP is calculated using the cooling load and the power input. The theoretical values are also shown for comparison. In all cases the actual COP is less than the theoretical COP. The condenser pressure is $1.2 \mathrm{MPa}(180$ Psi)and the evaporator pressure is $0.2 \mathrm{MPa}(30 \mathrm{Psi})$. The temperatures at the salient points of the refrigeration system are shown in Table 1. It is very much clear from the histogram shown below that the SUNISO 3GS + alumina nanoparticle mixture has the highest COP when compared with the other cases. The advantages of adding nanoparticle to the lubricant is manifold. It reduces the power consumption of the compressor and there is sub cooling of the nano-refrigerant in the condenser which in turn increases the COP. The Actual COP is calculated using the energy meter reading and the cooling load. For the calculation of theoretical COP the enthalpy values at the salient points are taken from P-h chart for R134a. 
Table 1: Temperatures at salient points

\begin{tabular}{|l|c|c|c|}
\hline \multicolumn{1}{|c|}{ Quantity } & $\begin{array}{c}\text { POE oil } \\
{ }^{\circ} \mathrm{C}\end{array}$ & $\begin{array}{c}\text { SUNISO 3GS oil } \\
{ }^{\circ} \mathrm{C}\end{array}$ & $\begin{array}{c}\text { SUNISO 3GS oil with } \mathrm{Al}_{2} \mathrm{O}_{3} \\
\text { nanoparticle }{ }^{\circ} \mathrm{C}\end{array}$ \\
\hline Temperature at the inlet to the compressor & 19 & 19 & 4 \\
\hline Temperature at the inlet to the condenser & 85 & 82 & 80 \\
\hline Temperature at the outlet of the condenser & 50 & 45 & 38 \\
\hline Temperature at the outlet of the expansion device & -7 & -8 & -7 \\
\hline Temperature at the inlet to the evaporator & -6 & -7 & -6 \\
\hline
\end{tabular}

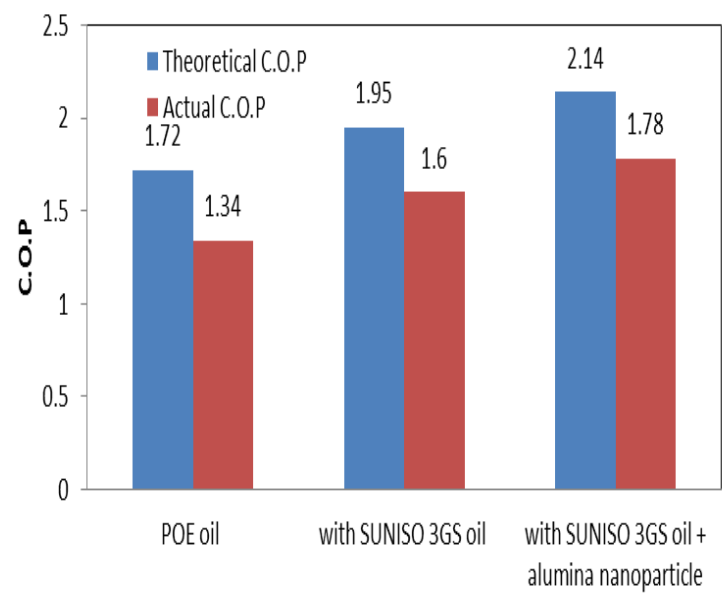

Figure 8. Comparison of Coefficient of Performance (COP) for the three cases

\section{Conclusions}

Extensive experimental studies have been conducted to evaluate the performance parameters of a vapour compression refrigeration system with different lubricants including nanolubricants. The conclusions derived out of the present study are(i) The R134a refrigerant and mineral oil mixture with nanoparticles worked normally (ii) Freezing capacity of the refrigeration system is higher with SUNISO 3GS + alumina nanoparticles oil mixture compared the system with POE oil (iii) The power consumption of the compressor reduces by $25 \%$ when the nanolubricant is used instead of conventional POE oil (iv) The coefficient of performance of the refrigeration system also increases by $33 \%$ when the conventional POE oil is replaced with nanorefrigerant $\mathrm{v}$ ) the energy enhancement factor in the evaporator is 1.53 .

\section{Nomenclature}

Cp specific heat

K Thermal conductivity

$\mathrm{T} \quad$ Temperature

$\mathrm{X} \quad$ mass fraction

h $\quad$ Enthalpy

hfg latent heat of vaporization

m mass

q heat flux

\section{Greek letters}

$\sigma$

surface tension

$\rho \quad$ Density

$\mu \quad$ Viscosity

$\omega \quad$ Nanoparticle concentration in the nanoparticle oil suspension

$\psi \quad$ Volume fraction of nanoparticle in the nanoparticle/oil suspension 


\section{Subscripts}

$\begin{array}{ll}\mathrm{f} & \text { liquid } \\ \mathrm{g} & \text { gas } \\ \mathrm{n} & \text { nanoparticle } \\ \mathrm{o} & \text { oil } \\ \mathrm{r} & \text { refrigerant } \\ \mathrm{n}, \mathrm{o} & \text { nanoparticle and oil } \\ \mathrm{r}, \mathrm{o} & \text { refrigerant and oil } \\ \mathrm{r}, \mathrm{n}, \mathrm{o} & \text { refrigerant, nanoparticle and oil }\end{array}$

\section{References}

Baustian, J.J., Pate, M.B., Bergles, A.E., 1988. Measuring the concentration of a flowing oil-refrigerant mixture: instrument test facility and initial results. ASHRAE Transactions, Vol. 94, No. 1, pp167-177.

Bi S., Guo K., Liu Z., 2011. Performance of a domestic refrigerator using $\mathrm{TiO}_{2}-\mathrm{R} 600$ a nanorefrigerant as working fluid. Energy Conversion and Management, Vol. 52, No. 1, pp. 733-737.

Bi S., Shi L. and Zhang L., 2007. Performance study of a domestic refrigerator using R134a/mineral oil/nano-TiO2 as working fluid. ICR07-B2-346.

Bi S., Shi L. and Zhang L., 2008. Application of nanoparticles in domestic refrigerators. Applied Thermal Engineering, Vol. 28, pp.1834-1843.

Brinkman, H.C., 1952. The viscosity of concentrated suspensions and solution. The Journal of Chemical Physics, Vol.20, pp. 571581.

Hamilton, R.L., Crosser, O.K., 1962. Thermal conductivity of heterogeneous two-component systems. Industrial and Engineering Chemistry Fundamentals, Vol. 1, No. 3, pp. 187-191.

Hao Peng et.al., 2010. Nucleate pool boiling heat transfer characteristics of refrigerant/oil mixture with diamond nano particles. International Journal of Refrigeration, Vol.33, pp. 347-358.

Jensen, M.K., Jackman, D.L., 1984. Prediction of nucleate pool boiling heat transfer coefficients of refrigerant-oil mixtures. Journal of Heat Transfer, Vol. 106, pp. 184-190.

Jwo et.al, 2009. Effect of nano lubricant on the performance of Hydrocarbon refrigerant system. J. Vac. Sci. Techno. B, Vol.27, No. 3, pp. 1473-1477.

Kedzierski, M.A., Kaul, M.P., 1993. Horizontal nucleate flow boiling heat transfer coefficient measurements and visual observations for R12, R134a, and R134a/ester lubricant mixtures. In: Proceedings of the 6th International Symposium on Transport Phenomena in Thermal Engineering, Vol. 1, pp. 111-116.

Kristen Henderson et.al, 2010. Flow boiling heat transfer of R134a based nano fluids in a horizontal tube. IJHMT, Vol.53, pp 944951.

Pak B.C., Cho, Y.I., 1998. Hydrodynamic and heat transfer study of dispersed fluids with submicron metallic oxide particles. Experimental Heat Transfer, Vol. 11, No. 2, pp. 151-170.

Pawel K. P., Jeffrey A.E. and David G.C., 2005. Nanofluids for thermal transport. Materials Today, pp. 36-44.

Bobbo S. et.al, 2010. Influence of nanoparticles dispersion in POE oils on lubricity and R134a solubility. International Journal of Refrigeration, Vol.33, pp. 1180-1186.

\section{Biographical notes}

N. Subramani is with the Department of Mechanical Engineering, TKM College of Engineering, Kerala, India

M. J. Prakash is with the Department of Mechanical Engineering, TKM College of Engineering, Kerala, India

Received December 2011

Accepted July 2012

Final acceptance in revised form August 2012 